\title{
'SOFT' SHORE PROTECTION BY A BEACH DRAIN SYSTEM
}

\author{
KARAMBAS Th.V. ${ }^{1, *}$ \\ IOANNIDIS D. ${ }^{2}$
}

\author{
${ }^{1}$ Department of Hydraulics and Environmental Engineering \\ School of Civil Engineering \\ Aristotle University of Thessaloniki, 54124 Thessaloniki,Greece \\ ${ }^{2}$ Department of Civil Engineering, T.E.I. of Serres \\ Terma Magnesias, 62124, Serres, Greece
}

Received: $12 / 02 / 09$

Accepted: 27/02/13 *to whom all correspondence should be addressed: e-mail: karambas@civil.auth.gr

\begin{abstract}
In this study, the effects of seepage flow in the swash zone on beach profile evolution under the wave action are examined numerically. The seepage flow is induced artificially by a porous drain pipe buried beneath swash zone parallel to the coastline. The system includes minimal environmental impact compared with the hard protection methods. A higher order Boussinesq model for breaking and non-breaking waves is extended in the swash zone and is coupled with a porous flow model, in order to take into account the influence of infiltration-exfiltration processes in the sediment transport. This influence is introduced in a simple and well-proven sediment transport formula by using a new modified Shields parameter, which is derived after the modification of the shear stress and the immerged sediment weight. In order to incorporate the suspended sediment transport rate, the depth-integrated transport equation for suspended sediment is solved. Model results are compared with experimental data. The agreement between numerical simulations and experiment is quite satisfactory. It is concluded that the beach drainage method is efficient for shore protection from erosion.
\end{abstract}

KEYWORDS: waves, swash, coastal erosion, beach drainage, numerical model, beach dewatering system.

\section{INTRODUCTION}

Beach Drainage System is a 'soft' shore protection method. A drainage system is installed under the beach face and parallel to the coastline to enhance beach accretion by artificially lowering the ground water table.

Bagnold (1940) first described the role of permeability on the beach morphology. Bagnold's experiments implied that with enhanced infiltration of wave uprush on the beach face, onshore transport of sediment may be facilitated while the offshore transport of sediment is reduced.

Machemehl et al. (1975) conducted the first experimental test of a beach dewatering system. By installing a polyvinyl chloride (PVC) drain they obtained the lowering of the groundwater level and they observed that beach drainage greatly enhanced the rate of sediment deposition on the foreshore and accelerated the rate of profile recovery following an erosive event.

The first field test was conducted by Chappel et al. (1979) in Australia, while the first patent of a Beach Drainage System was registered by the Danish Geotechnical Institute in 1985 (Vesterby, 1991; 1994).

The importance of the beach water table in controlling profile change has been the object of several recent investigations in Europe, USA and Australia (Turner and Leatherman, 1997; Bowman et al., 2007, Ciavola et al., 2008). Some sites seem to experience no beach response whereas in other cases a shoreline advancement of a few meters was observed, but still there is no full scientific 
evidence that the systems can replace traditional coastal defences (Bruun, 2005). Many field experiments were carried out by the Danish Geotechnical Institute, often in collaboration with other institutions (Vesterby, 1995) and by Italian researchers (Ciavola et al., 2009; Veltri et al., 2009).

So far there are no published design guidelines in this sense, therefore a "rule-of-thumb" is the approach that installers prefer, which is clearly not satisfactory from an engineering viewpoint.

The transport of sediment across the beach face is performed by wave uprush and backwash. The upwash moves sand on-shore while the backwash transports it offshore. The wave motion also interacts with the beach groundwater flow. Seawater may infiltrate into the sand at the upper part of the beach (around the shoreline) during swash wave motion if the beach groundwater table is relatively low. In contrast, groundwater exfiltration may occur across the beach with a high water table. Such interactions have a considerable impact on the swash sediment transport.

Two mechanisms are expected to be important in altering the uprush and backwash sediment transport: sediment stabilisation and boundary layer thinning due to infiltration on the uprush, and sediment destabilisation and boundary layer thickening due to exfiltration on the backwash (Butt et al., 2001; Karambas, 2003). Seawater infiltration under a low water table was found to enhance onshore sediment transport, whereas groundwater exfiltration under a high water table promotes offshore sediment transport. Thus it is expected that an artificially lowering the ground water table, with a drainage system, advances accretion of sediments for accretive wave conditions, and retards beach erosion for erosive waves. The above conclusion is confirmed by field and laboratory measurements (Law et al., 2002; Sato et al., 2003).

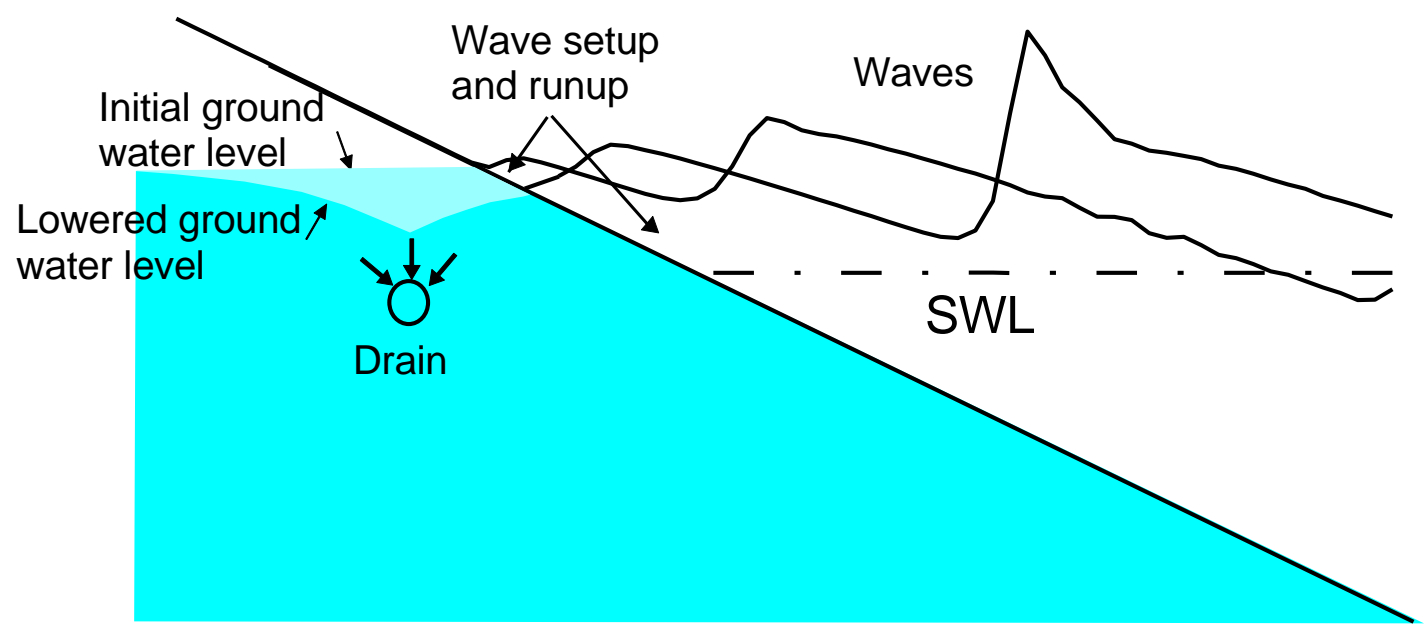

Figure 1. The beach drainage system

The pipes of a beach drainage system are buried in the beach parallel to the coastline and drain the seawater away to a collector sump and pumping station. The collected seawater may be discharged back to sea but can also be used to various applications (marinas oxygenation, desalination plants, swimming pools...).

The system includes minimal environmental impact compared with the hard protection methods.

\section{COUPLING OF A BOUSSINESQ MODEL TO A POROUS FLOW MODEL}

A combined model with interaction between the external and internal wave motion is applied here. The model is composed in such a way that an external layer of water overlaps a layer of water governed by the equations for media flow (Figure 2). The external wave motion causes pressure differences resulting in a flow between the external volume of water and the volume in the permeable bed. Both the volume-flux of this exchange and the momentum of this flow are incorporated in the basic equations as source terms. 


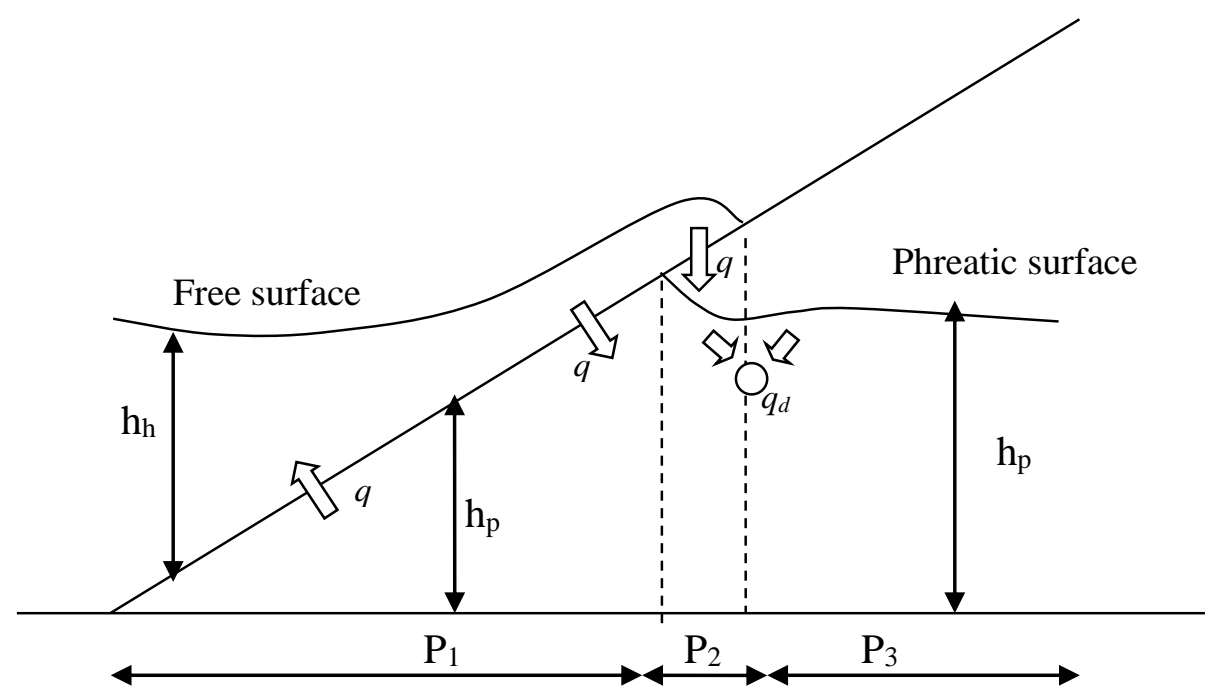

Figure 2. Area's with different treatment for the coupling of the hydraulic model to the porous flow model.

\section{Boussinesq-type wave model}

In order to simulate the external wave motion, we used an existing Boussinesq type model developed by Karambas and Koutitas (2002).

The higher order Boussinesq-type equations for breaking and non breaking waves derived by Karambas and Koutitas (2002) are written:

$$
\begin{aligned}
& \frac{\partial \zeta}{\partial t}+\frac{\partial(U h)}{\partial x}=0 \\
& \frac{\partial U}{\partial t}+\frac{1}{h} \frac{\partial M_{u}}{\partial x}-\frac{1}{h} U \frac{\partial(U h)}{\partial x}+g \frac{\partial \zeta}{\partial x}=\frac{\left(d^{2}+2 d \zeta\right)}{3} \frac{\partial^{3} U}{\partial x^{2} \partial t}+d_{x} h \frac{\partial^{2} U}{\partial x \partial t} \\
& +\frac{d^{2}}{3}\left(U \frac{\partial^{3} U}{\partial x^{3}}-\frac{\partial U}{\partial x} \frac{\partial^{2} U}{\partial x^{2}}\right)+d \frac{\partial \zeta}{\partial x} \frac{\partial^{2} U}{\partial x \partial t}+d d_{x} U \frac{\partial^{2} U}{\partial x^{2}}+ \\
& +d_{x} \frac{\partial \zeta}{\partial x} \frac{\partial U}{\partial t}-d \frac{\partial^{2}}{\partial x \partial t}\left(\delta \frac{\partial U}{\partial x}\right)+ \\
& +B d^{2}\left(\frac{\partial^{3} U}{\partial x^{2} \partial t}+g \frac{\partial^{3} \zeta}{\partial x^{3}}+\frac{\partial^{2}\left(U \frac{\partial U}{\partial x}\right)}{\partial x^{2}}\right) \\
& +2 B d d_{x}\left(\frac{\partial^{2} U}{\partial x \partial t}+g \frac{\partial^{2} \zeta}{\partial x^{2}}\right)-\frac{\tau_{b}}{h}+E
\end{aligned}
$$

where

$$
M_{u}=(d+\zeta) u_{o}^{2}+\delta\left(c^{2}-u_{o}^{2}\right)
$$

and, the subscript $t$ denotes differentiation with respect to time, the subscript $x$ denotes differentiation with respect to space, $d$ is the still water depth, $U$ is the depth-averaged horizontal velocity, $\zeta$ is the surface elevation, $\delta$ is the roller thickness, $h=d+\zeta$, $u_{0}$ is the bottom velocity, $c$ is the roller celerity, $g$ is the gravitational acceleration, $\tau_{b}$ is the bed shear stress, and $E$ is the eddy viscosity term. The dispersion coefficient, $B$ is set to the value $1 / 15$, which provides linear dispersion characteristics to a Padé $[2,2]$ expansion of the Stokes linear dispersion relation.

In the above model, wave energy dissipation due to wave breaking has been introduced using the surface roller concept. The concept results in an additional convective term in the momentum equation which accounts for the non-uniform vertical distribution of the horizontal velocity (see 
Schäffer et al., 1993 and Karambas and Koutitas, 2002, for more details). The breaking criterion and the detection of the roller region is described in Schäffer et al. (1993). The instantaneous bottom shear stresses term is approximated by the use of a quadratic law. For the estimation of the bed roughness $K_{N}$, a function of the Shields parameter, ripple height $\eta_{r}$ and length $\lambda_{r}$ is adopted according to Nielsen (1997). Details are found in Karambas and Koutitas (2002).

The eddy viscosity concept is adopted in order to simulate the dissipation due to turbulence in the swash zone (the run-down point is considered as the offshore limit of the swash zone). The eddy viscostity term in the right hand side of equation (1b) is written:

$\mathrm{E}=\frac{1}{\mathrm{~h}} \frac{\partial}{\partial \mathrm{x}}\left(v_{s} \frac{\partial U}{\partial x}\right)$

where $v_{s}$ is the swash zone eddy viscosity coefficient estimated from (Zelt, 1991):

$v_{s}=\ell^{2}\left|\frac{\partial U}{\partial x}\right|$

where $\ell$ is a length scale.

The length scale $\ell$ is related to the total water depth $h$ through $\ell=2 h$ (Zelt, 1991). Near the shore, where $\ell$ is less than one node spacing. Under this condition the length scale cannot be resolved on the grid, so it is increased sufficiently to avoid numerical difficulties; $\ell$ is taken equal to $\ell=2 \mathrm{dx}$, where $\mathrm{dx}$ is the grid size. The above artificial viscosity technique is applied near the front of the broken wave where $\partial U / \partial x<0$.

The 'dry bed' boundary condition is used to simulate runup. The condition, at the point $\mathrm{i}$, is written:

if $(d+\zeta)_{i-1}<0.00001 \mathrm{~m}$ and $U_{i}>0$ then $\zeta_{i}=-d$ and $U_{i}=0$

and

if $(d+\zeta)_{i}<0.00001 \mathrm{~m} \quad$ and $U_{i}<0$ then $\quad \zeta_{i}=-d$ and $U_{i}=0$

which is very simple and very easily incorporated in a nonlinear wave model.

The numerical solution of the Boussinesq-type equations is based on an accurate higher order numerical scheme, which has been developed by Wei and Kirby (1995). They used a fourth-order predictor-corrector scheme for time stepping and discretizing the first-order spatial derivatives to fourth-order accuracy. This discretization automatically eliminates error terms that would be of the same form as the dispersive terms, and which must therefore be corrected for if lower order scheme are used.

\section{Porous flow model}

The following long wave equations are used for the porous flow model (Van Gent, 1994; 1995; Karambas, 2003):

$$
\begin{aligned}
& \left(1+c_{A}\right) \frac{\partial h_{p} u_{p}}{\partial t}-c_{A} u_{p} \frac{\partial h_{p}}{\partial t}+\frac{1}{\lambda} \frac{\partial h_{p} u_{p}^{2}}{\partial x}+\lambda g \frac{\partial \frac{1}{2} h_{p}^{2}}{\partial x}+\lambda g h_{p}\left(a u_{p}+b u_{p}\left|u_{p}\right|\right)=-\frac{q q_{x}}{\lambda} \\
& \frac{\partial h_{p}}{\partial t}+\frac{1}{\lambda} \frac{\partial h_{p} u_{p}}{\partial x}=-\frac{q}{\lambda}
\end{aligned}
$$

where $q\left(\mathrm{~m} \mathrm{~s}^{-1}\right)$ is the volume-flux of the flow between both layers and $q_{x}$ is the horizontal component of the velocity of this flow which is obtained by assuming that this flow is perpendicular to the slope, $h_{p}$ is the thickness of the water layer in porous medium, $u_{p}$ is the depth-averaged filter/discharge velocity in this layer, $a, b$ are the Forchheimer coefficients, $c_{A}$ is the coefficient for added mass $\left(c_{A}=0\right)$ and $\lambda$ is the porosity.

According to van Gent $(1994 ; 1995)$ for the external wave motion two extra terms $S_{c}$ and $S_{m}$ are introduced in the right-hand side of the continuity and momentum equations:

$S_{c}=q \quad$ in the right-hand side of the continuity Boussinesq equation 
$S_{m}=\frac{q q_{x}}{d+\zeta} \quad$ in the right-hand side of the momentum Boussinesq equation

where $\zeta$ is the (wave) free surface elevation.

For the coupling of the hydraulic model to the porous flow model the internal area of the swash zone is sub-divided into three area's with different treatment (Figure 2).

The part of the porous medium that is overlapped by the hydraulic model is area $P_{1}$ in which the thickness of the porous layer $h_{p}$ is time-independent and consequently $\partial h_{p} / \partial t=0$. Thus the inflow rate $q$ is estimated from: $q=-\partial\left(u_{p} h_{p}\right) / \partial x$. In this area $\left(P_{1}\right)$ the term $\lambda g \partial\left(1 / 2 h_{p}^{2}\right) / \partial x$ becomes $\lambda g$ $\partial\left(1 / 2\left(h_{h}+h_{p}\right)^{2}\right) / \partial x$, where $h_{h}$ is the thickness of the hydraulic layer, $h_{h}=h=d+\zeta$ (Figure 2). In area $P_{2}$ infiltration $q$ through a partially saturation area appears. In area $P_{3}$ there is no infiltration or direct flow from the hydraulic model and consequently $q=0$.

In area $P_{2}$ the inflow rate at the beach $q$ is computed following Packwood (1983):

$q=\lambda \frac{\partial \eta}{\partial t}$

where $\eta$ is the depth of the free surface in porous medium.

More details can be found in Karambas (2003).

The infiltration velocity in area P1 is increased by the amount induced by the pipe discharge $q_{d}$ (Sato et al., 1996).

$v_{d}=\frac{a q_{d}}{\pi\left(x^{\prime 2}+a^{2}\right)}$

where $v_{d}$ is the velocity of the flow induced along $x^{\prime}$-axis and $\alpha$ is the distance from the sea bottom to the pipe (Figure 3).

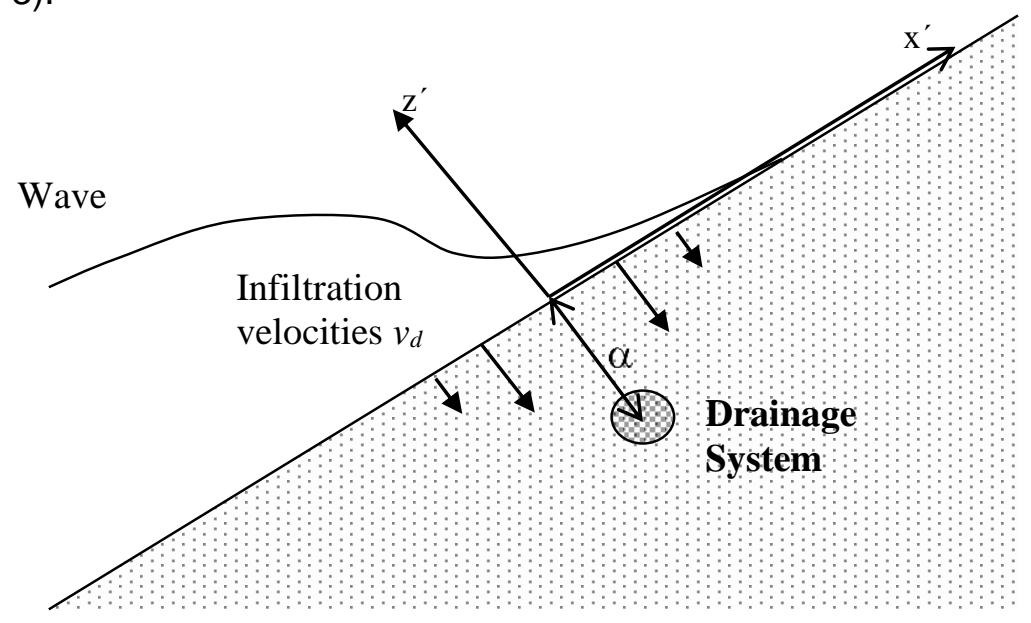

Figure 3. Infiltration velocities (reference system $x^{\prime}-z^{\prime}$ )

\section{SEDIMENT TRANSPORT RATES IN THE SWASH ZONE}

Sediment transport rates in the swash zone are estimated by adopting two well-proven sediment transport formulae both for bed and suspended load. The influence of swash infiltration-exfiltration on sediment transport is introduced by using a modified Shields parameter $\theta$, which is derived after the modification of the shear stress and the immerged sediment weight $W$.

The non-dimensional bed load sediment transport rate $Q$ is considered propotional to $\theta^{3 / 2}$ and can be estimated from a slightly modified Meyer-Peter and Müller fomula (Butt et al., 2001; Larson et al., 2001): 


$$
Q=\frac{q_{b}(1-\lambda)}{\sqrt{(s-1) g d_{50}^{3}}}=\frac{9.0}{1+\frac{\tan \beta}{\tan \phi}} \theta_{w}^{3 / 2} \frac{U}{|U|}
$$

where $q_{b}$ is the bed load transport rate, $U$ is the wave bottom velocity, $s$ is the specific density of the sediment, $\phi$ is the angle of internal friction (about $30 \mathrm{deg}$ ), $\tan \beta$ is the local beach slope (positive during the uprush phase and negative during the backwash phase), $d_{50}$ is the median grain diameter and $\theta$ is the Shields parameter: $\theta_{w}=\frac{\tau_{w}}{W_{w}}$ where $\tau_{w}$ is the bed shear stress and $W_{w}$ is the immerged sediment weight per unit volume of the bed.

The immerged sediment weight $W_{w}$ per unit volume of the bed is adjusted for infiltration-exfiltration by simply adding the weight loss or gain caused by seepage (Nielsen, 1997; Turner and Masselink, 1998):

$$
W_{w}=W_{o}-0.5 \rho g d_{50} \frac{w}{K}=\rho g d_{50}(s-1)-0.5 \rho g d_{50} \frac{W}{K}
$$

where $w$ is the vertical velocity in the bed (positive upwards) and $\rho$ is the density of the water.

In order acount for the effects of increased shear stress due to infiltration Nielsen (1997) assumed a linear relation between shear stress and the relative vertical velocity $(w / U)$. Turner and Masselink (1998) derived an alternative relationship for the ratio of shear stress in the presentce of vertical flow (Butt et al., 2001; Masselink and Hughes, 1998; Nielsen, 1997; Turner and Masselink, 1998):

$$
\tau_{w}=\tau_{o}\left(\frac{\Phi}{e^{\Phi}-1}\right)
$$

where

$$
\tau_{\mathrm{o}}=0.125 \rho f U^{2}
$$

and

$$
\Phi=\frac{2.0}{f} \frac{w}{|U|}
$$

where $f$ is a friction factor for the case of no through-bed flow, which is estimated using a formula for steady flow, since it is preferred to treat the flow in the swash zone as quasi-steady (uprush and backwash are considered as two separate quasi-steady flows) (Butt et al., 2001):

$$
f=1.28\left(\log \frac{11.1 h_{h}}{K_{N}}\right)^{-2}
$$

where $K_{N}$ is the bed roughness.

In this way (i.e. through equations 10 and 11) the two main mechanisms: a. sediment stabilisation and boundary layer thinning due to infiltration on the uprush, and b. sediment destabilisation and boundary layer thickening due to exfiltration on the backwash, are taken into account (for more details see Karambas, 2003).

Suspended sediment transport rate is incorporated by solving the depth-integrated transport equation for suspended sediment. Here we adopt the transport equation proposed by Kobayashi and Tega (2002) and Karambas (2006):

$$
\frac{\partial\left(\boldsymbol{h}_{\boldsymbol{h}} \boldsymbol{C}\right)}{\partial \boldsymbol{t}}+\frac{\partial\left(\boldsymbol{h}_{\boldsymbol{h}} \boldsymbol{C} \boldsymbol{U}_{s}\right)}{\partial \boldsymbol{x}}=\boldsymbol{S}-\boldsymbol{w}_{s} \boldsymbol{C}
$$

where $C$ is the depth-averaged volumetric sediment concentration, $U_{s}$ is the horizontal sediment velocity, $S$ is the upward sediment suspension rate from the bottom and $w_{s}$ is the sediment fall velocity. The horizontal sediment velocity $U_{s}$ is assumed to be given by $U_{s}=\left(U-w_{s}\right)$. 
The suspension rate $S$ per unit horizontal area is related to the wave energy dissipation (Kobayashi and Tega, 2002; Karambas, 2006):

$$
S=S_{B}+S_{f} ; \quad S_{B}=\frac{e_{B} D_{B}}{\rho g(s-1) h_{h}} ; \quad S_{f}=\frac{e_{f} D_{f}}{\rho g(s-1) h_{h}}
$$

where $D_{B}$ is the energy dissipation rate due to wave breaking (estimated from Karambas 2006, by adopting the mixing length hypothesis), $D_{f}$ is the energy dissipation rate due to bottom friction ( $D_{f}$ $\left.=0.125 \rho f|\boldsymbol{U}|^{3}\right), e_{B}$ is the suspension efficiency for $D_{B}$ and $e_{f}$ is the suspension efficiency for $D_{f}$ given in Kobayashi and Tega (2002) and Karambas (2006).

The suspended transport rate is estimated from:

$q_{s}=h_{h} C U_{s}$

The total time averaged load in the submerged part of the beach is obtained from by:

$q_{t}=q_{b}+q_{s}$

Inside the surf zone the sediment transport rates are calculated according to Karambas and Koutitas (2002).

The bed profile changes are calculated by solving the conservation of sediment transport equation.

\section{APPLICATIONS}

The effects of a beach drainage system on beach morphology evolution have been studied by a series of experiments by Law et al. (2002). In those experiments transient beach profiles with and without seepage were recorded at different time intervals from the start of the wave attack. Experiments were performed in a wave flume $45 \mathrm{~m}$ long and $1.6 \mathrm{~m}$ wide. The drain pipe was a 30 $\mathrm{mm}$ diameter PVC pipe with small holes of $1.5 \mathrm{~mm}$ diameter drilled around the pipe. The beach slope was $1: 15$ and the median grain size $d_{50}$ was $0.31 \mathrm{~mm}\left(d_{50}=0.31 \mathrm{~mm}\right)$. The drain pipe was buried at different location below swash zone. In the experiment that is reproduced here the thickness of the sand layer cover was $10 \mathrm{~cm}$ and the average flow rate $q_{d}=0.48 \mathrm{I} \mathrm{s}^{-1} \mathrm{~m}^{-1}$. The following erosive wave conditions were applied: deep water wave height $H_{0}=19.5 \mathrm{~cm}$ and period $T=1.5 \mathrm{~s}$.

In Figure 4 calculated cross-shore transport rate are shown with and without the effects of drainage. It is quite clear that due to the beach drainage system the offshore cross-shore transport rate is reduced, especially near shoreline. Since infiltration enhance on-shore sediment transport and exfiltration promotes offshore sediment transport (Karambas, 2003), the artificially lowering the ground water table with the drainage system, reduces the offshore transport, by reducing the exfiltration of the seawater.

The offshore sediment transport is the reason of the beach erosion and consequently its reduction reduces the expected coastal erosion, under the erosive wave conditions. In Figure 5 the bed profile evolution, with and without drain system, is presented. It is obvious that the drain system retards beach erosion for erosive waves. Without the drain system beach recession was found to be about $0.4 \mathrm{~m}$, while, with the system, measurements showed a recession about $0.25 \mathrm{~m}$. The amount of sediment that has been gained near swash zone, has been lost from the inner surf zone, onshore the longshore bar. In the upper beach a berm has been formed wile the slope is generally steeper than the comparable slope without drainage. This has also been confirmed by recent field measurements by Bowman et al. (2007). 

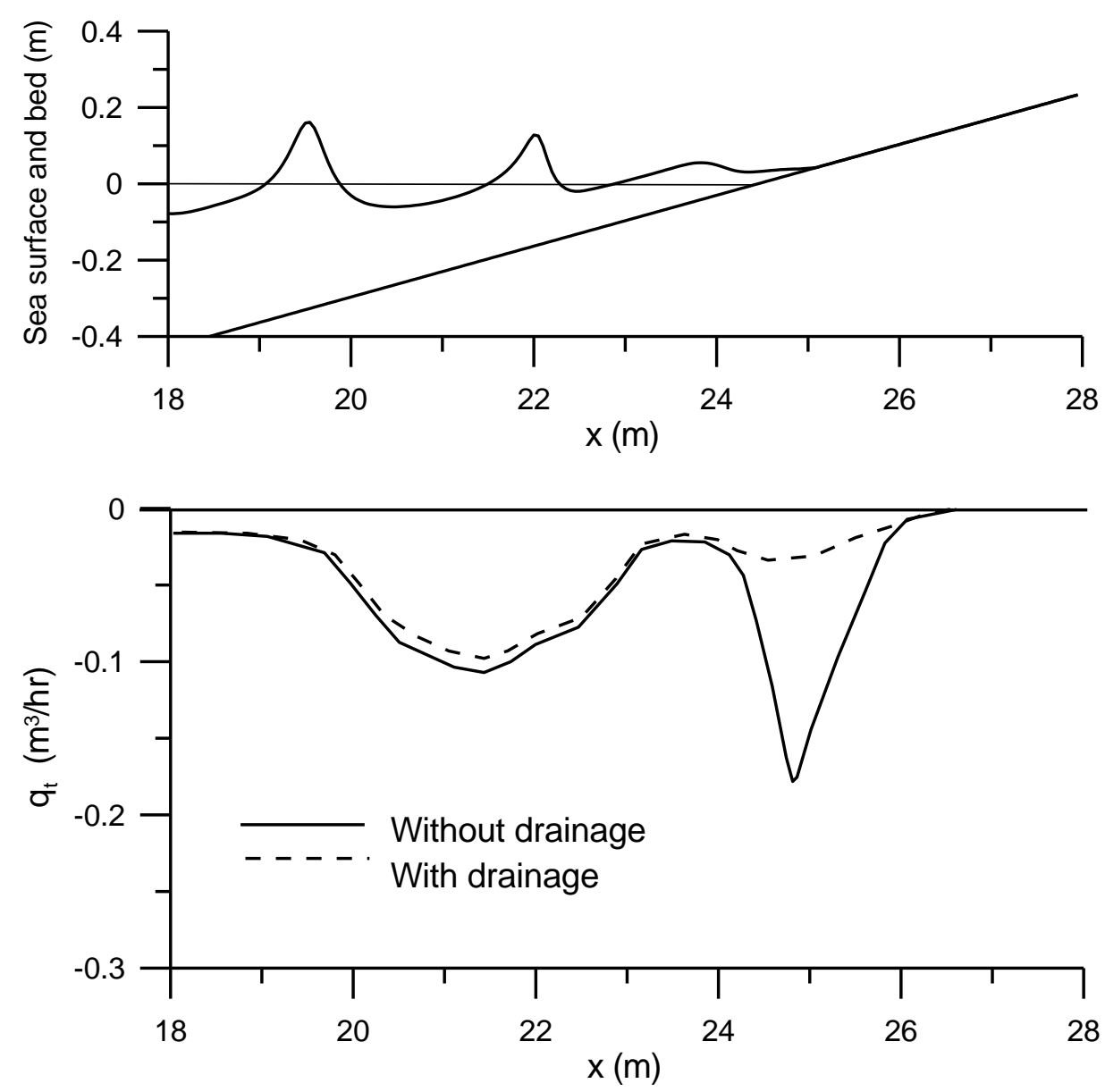

Figure 4. Incident waves and calculated cross-shore total transport rates (Law et al., 2002 experiments)

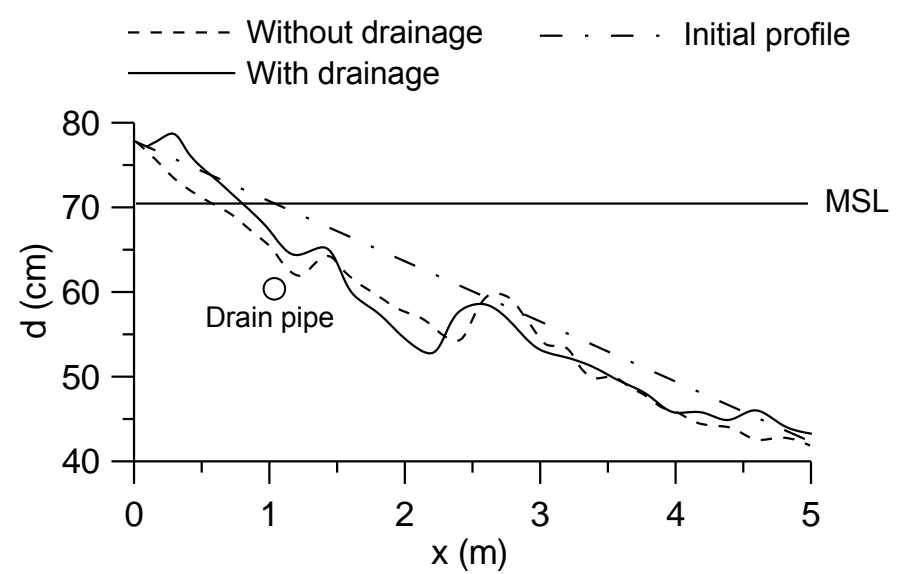

Figure 5. Bed profile evolution in Law et al. (2002) experiments, with and without drainage

In Figure 6 model results are compared with experimental data. The agreement between experimental measurements and numerical results is very good. 


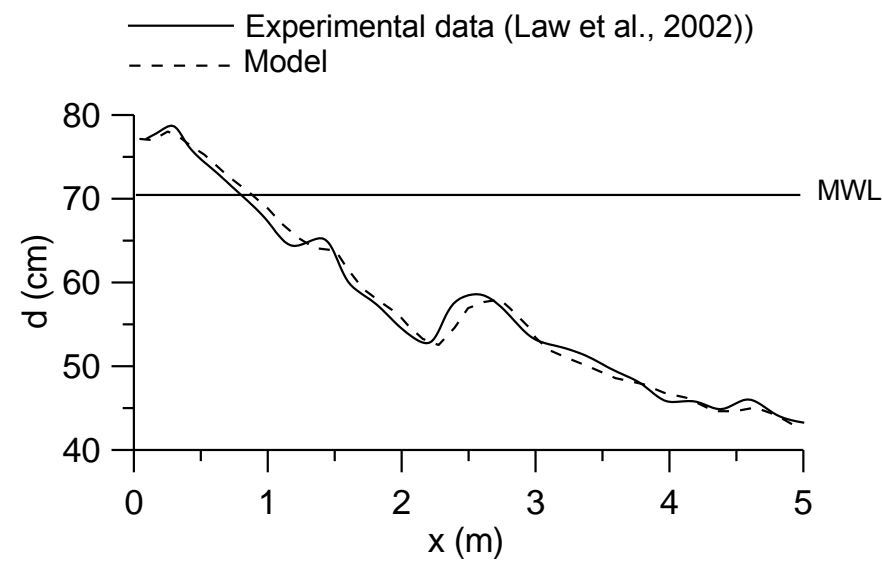

Figure 6. Comparison between model results and experimental data by Law et al. (2002)

\section{CONCLUSIONS}

In this study, the effects of seepage flow in the swash zone on beach profile evolution under the wave action are examined numerically. The seepage flow is induced artificially by a porous drain pipe buried beneath swash zone parallel to the coastline. To take into account of the infliltrationexfiltration processes, a modified Shields parameter is used to account the effects of stabilization or destabilization of the surface layers and boundary layer thickening or thinning. Due to the beach drainage system the offshore cross-shore transport rate is reduced, especially near shoreline. This reduction is expected to retard beach erosion for erosive waves. Model results are compared with experimental data. The agreement between numerical simulations and experiment data is quite satisfactory. Thus, the beach drainage can be considered as an efficient and promising method for shore protection from erosion.

\section{ACKNOWLEDGEMENTS}

The present work was undertaken within the framework of the project 'Environmental Hydraulics'. The project was co-funded by the European Social Fund (75\%) and National Resources (25\%) - (EPEAEKIII) ARCHIMEDES.

\section{REFERENCES}

Bagnold R.A. (1940), Beach formation by waves: some model experiments in a wave tank, Journ. Inst. Civ. Eng., 15, 27-52.

Bowman D., Ferri S. and Pranzini E. (2007), Efficacy of beach dewatering-Alassio, Italy, Coastal Engineering, 54(11), 791-800.

Bruun P. (2005), Beach drain. In: Schwartz, M.L. (Ed.), Encyclopedia of Coastal Science, Springer, pp. 138-140.

Butt T, Russell P. and Turner I. (2001). The influence of swash infiltration-exfiltration on beach face sediment transport: onshore or offshore?, Coastal Engineering, 42, 35-52.

Chappel J., Eliot I.G., Bradshaw M.P. and Lonsdale E. (1979), Experimental control of beach face dynamics by watertable pumping, Engineering Geology, 14, 29-41.

Ciavola P., Vicinanza D. and Fontana E. (2008), Beach drainage as a form of shoreline stabilization: Case studies in Italy. Int. Conf. on Coastal Engineering, ed. J. McKee Smith, World Scientific, vol. 3, 2646-2658.

Ciavola P., Fontana E. and Vicinanza D. (2009), Performance of a beach drainage system at Lido Adriano (Ravenna - Italy), 33rd IAHR Congress: Water Engineering for a Sustainable Environment, International Association of Hydraulic Engineering \& Research (IAHR).

Karambas Th.V. and Koutitas C. (2002), Surf and swash zone morphology evolution induced by nonlinear waves, J. of Waterway, Port, Coastal, and Ocean Eng., 128(3), 102-113.

Karambas Th.V. (2003), Modelling of infiltration - exfiltration effects of cross-shore sediment transport in the swash zone, Coastal Engineering Journal, 45(1), 63-82.

Karambas Th.V. (2006), Prediction of sediment transport in the swash zone by using a nonlinear wave model, Continental Shelf Research, 26(5), 599-609. 
Kobayashi N. and Johnson B.D. (2001), Sand suspension, storage, advection, and settling in surf and swash zones, Journal of Geophysical Research, 106(C5), 9363-9376.

Kobayashi N. and Tega Y. (2002), Sand suspension and transport on equilibrium beach, Journal of Waterway, Port, Coastal, and Ocean Engineering, 128(6), 238-248.

Larson M., Kubota S. and Erikson L. (2001), A model of sediment transport and profile evolution in the swash zone, Coastal Dynamics '01, ASCE, Lund, pp. 908-917.

Law A.W-K., Lim S-Y and Liu B-Y (2002), A note on transient beach evolution with artificial seepage in the swash zone, Journal of Coastal Research, 18(2), 379-387.

Masselink G. and Hughes M.G. (1998), Field investigation of sediment transport in the swash zone, Cent. Shelf Res. 18(10), 1179-1199.

Machemehl J.L., French T.J. and Huang N.E. (1975), New method for beach erosion control, Engineering in the Oceans, ASCE Speciality Conference, pp. 142-160.

Nielsen P. (1997), Coastal groundwater dynamics, Proc. Coastal Dynamics '97, Plymouth. ASCE, pp. 546-555.

Nielsen P., Robert S., Moeller-Christiansen B. and Oliva P. (2001), Infiltration effects on sediment mobility under waves, Coastal Engineering, 42(2), 105-114.

Nielsen P. (2002), Shear stress and sediment transport calculations for swash zone modeling, Coastal Engineering, 45(1), 53-60.

Packwood A.R. (1983), The influence of beach porosity on wave uprush and backwash, Coastal Engineering, 7(1), 29-40.

Sato M., Fukushima T., Nishi R. and Fukunaga M. (1996), On the change of velocity field in nearshore zone due to coastal drain and the consequent beach transformation, Proc. $25^{\text {th }}$ International Conference on Coastal Engineering 1996, ASCE, pp. 2666-2676.

Sato M., Nishi R., Nakamura K. and Sasaki T. (2003), Short-term field experiments on beach transformation under the operation of a coastal drain system, Soft Shore Protection, Kluwer Academic Publishers, pp 171-182.

Schäffer H.A., Madsen P.A. and Deigaard R. (1993), A Boussinesq model for waves breaking in shallow water, Coastal Engineering, 20, 185-202.

Turner I.L. and Leatherman S.P. (1997), Beach Dewatering as a 'Soft' Engineering Solution to Coastal Erosion-A History and Critical Review, Journal of Coastal Research, 13(4), 1050-1063.

Turner I.L. and Masselink G. (1998), Swash infiltration-exfiltration and sediment transport, J. Geophys. Res, 103(C13), 30813-30824.

Van Gent M.R.A. (1994), The modeling of wave action on and in coastal structures, Coastal Engineering, 22, 311-339.

Van Gent M.R.A. (1995), Wave Interaction with Permeable Coastal Structures, Ph. D. Thesis, Delft University of Technology.

Veltri P., Verbeni B., Pugliese Carratelli E. (2009), An Italian Experience on BDS: Test Sites in Ostia and in Procida. 33rd IAHR Congress: Water Engineering for a Sustainable Environment, International Association of Hydraulic Engineering \& Research (IAHR).

Vesterby H. (1991), Coastal drain system: a new approach to coastal restoration. Proceedings of GEOCoast '91, pp. 651-654.

Vesterby H. (1994), Beach face dewatering-the European experience. Alternative Tecnologies in Beach Preservations. Proceedings of the 1994 National Conference on Beach Preservation Technology, pp. 53-68.

Vesterby $\mathrm{H}$. (1995), Beach face dewatering-the eco-friendly approach to coastal restorating. 4th Int. Conference Copedec'95 1: 83-96, Rio de Janeiro, Brazil.

Wei G. and Kirby J.T., (1995), Time-dependent numerical code for extended Boussinesq equations, Journal of Waterway, Port, Coastal and Ocean Engineering, 121(5), 251-261.

Zelt J.A. (1991), The run-up of nonbreaking and breaking solitary waves, Coastal Engineering, 15(3), 205-246. 